\title{
Pengembangan Modul Pembelajaran Pendidikan Agama Islam (PAI) Kelas IV Madrasah Ibtidaiyah
}

\author{
Laila Nursafitri $^{1)}$, Widi Widaryanto ${ }^{2)}$, Ahmad Zubaidi ${ }^{3)}$ \\ Sekolah Tinggi Agama Islam (STAI) Darussalam Lampung \\ *Corresponding author E-mail: laila.nursafitri87@gmail.com
}

Keywords: modul pembelajaran, pendidikan agama islam, madrasah ibtidaiyah, sekolah dasar

\section{Abstrak}

\begin{abstract}
Modul pembelajaran menjadi salah satu alternatif media pembelajaran cetak (printed) bagi siswa dalam belajar. Penelitian ini bertujuan untuk mengembangkan modul pembelajaran Pendidikan Agama Islam (PAI) kelas IV Madrasah Ibtidaiyah. Pengembangan modul pembelajaran dilaksanakan dalam enam tahap, yaitu (1) merumuskan masalah/tujuan penelitian, (2) melakukan studi pendahuluan, (3) merancang pengembangan, (4) melaksanakan pengembangan, (5) mengevaluasi produk, analisis data, dan refleksi, dan (6) menyusun laporan hasil penelitian. Validasi produk dilakukan dengan teknik focus group discussion (FGD). Peserta FGD peserta terdiri dari dosen dan guru pengampu mata pelajaran. Uji coba dilakukan dengan eksperimen The One Group Pretest-Posttest Design. Hasil uji coba menunjukkan peningkatan nilai rerata siswa. Rerata nilai pretes sebesar 60 mengalami kenaikan rerata nilai sebesar 86,7. Dengan demikian dapat dikatakan bahwa modul pembelajaran PAI ini efektif digunakan dalam pembelajaran.
\end{abstract}

Keywords: modul pembelajaran, pendidikan agama islam, madrasah ibtidaiyah, sekolah dasar

\section{Abstract}

Keywords: Learning Learning module to be one of print media learning for students. This study aims to Module, $\quad$ Islamic develop learning modules for Islamic Education (PAI) grade IV Madrasah Ibtidaiyah. Education, Madrasah Development of learning modules implemented in six phases: (1) formulating the Ibtidaiyah. problem/research objectives, (2) conducting preliminary studies; (3) designing development; (4) implement development; (5) evaluating products, data analysis, and reflection; and (6) reporting the research result. Product validation with focus group discussion (FGD) techniques. FGD participants are lecturer and subject matter teachers. The trial through The One Group Pretest-Posttest Design experiment. The results showed that students mean value increased. The mean of score 60 increased to 86.7. It can be said that this PAI learning module effectively used in learning.

Keywords: Learning Module, Islamic Education, Madrasah Ibtidaiyah @ Inventa:Jurnal Pendidikan Sekolah Dasar Copy Right

\section{Pendahuluan}

Pembelajaran merupakan proses yang dilakukan oleh siswa dalam rangka meningkatkan pengetahuan dan keterampilan. Dalam proses tersebut dibutuhkan berbagai sumber dan media yang dapat menjadi jembatan pemahaman bagi siswa. Media merujuk pada apa saja yang membawa informasi antara sebuah sumber dan sebuah penerima, tujuannya adalah untuk memudahkan komunikasi dan belajar (Smaldino et al., 2012). Media membawa peran penting sebagai pembawa pesan bagi siswa. Melalui media, pesan dapat tersaji 
dengan lebih jelas sehingga dapat Setyosari dan Effendi (Ahdianto, 2016) memperlancar proses belajar. Selain itu, mengemukakan bahwa pembelajaran dengan pengggunaan media dalam pembelajaran berpengaruh terhadap motivasi belajar siswa (Srinadi, 2016; Alannasir, 2016; Putri, 2017). Media pembelajaran juga dapat membuat peserta didik lebih banyak melakukan kegiatan belajar, dan aktivitas lainnya seperti mengamati, melakukan, mendemonstrasikan, dan sebagainya.

Modul pembelajaran menjadi salah satu alternatif media pembelajaran cetak (printed) bagi siswa dalam belajar. Modul merupakan salah satu bentuk bahan ajar yang dikemas secara utuh dan sistematis, didalamnya memuat seperangkat pengalaman belajar yang terencana dan didesain untuk membantu siswa menguasai tujuan belajar yang spesifik (Rahdiyanta, 2016). Melalui modul diharapkan siswa mampu mencapai tujuan pembelajaran yang telah ditetapkan. Selain itu, melalui modul siswa diharapkan mampu belajar dan memperluas wawasannya secara mandiri. Seperti yang disampaikan oleh Prastowo (2011) bahwa tujuan penggunaan modul dalam pembelajaran adalah (1) siswa mampu belajar secara mandiri atau dengan bantuan guru seminimal mungkin, (2) peran guru tidak mendominasi dan tidak otoriter dalam pembelajaran, (3) melatih kejujuran siswa, (4) mengakomodasi berbagai tingkat dan kecepatan belajar siswa, dan (5) siswa dapat mengukur sendiri tingkat penguasaan materi yang dipelajari.

modul bersifat dinamis dan kreatif karena siswa dituntut belajar dengan giat dalam memecahkan masalah yang diajukan dan siswa diarahkan pada penemuan yang memuat kreatifitas daya pikirnya. Siswa akan lebih kreatif dalam menumbuhkan daya nalarnya dengan belajar menggunakan modul pembelajaran. Modul pembelajaran memiliki beberapa karakteristik yang menjadi kelebihannya. Karakteristik modul meliputi: (1) Self instructional, (2) Self Contained, (3) Stand alone (berdiri sendiri), (4) Adaptif, dan (5) User friendly (Rahdiyanta, 2016).

Pendidikan Agama Islam (PAI) bertujuan untuk menumbuhkan dan meningkatkan keimanan melalui pemberian dan pemupukan pengetahuan, penghayatan, pengamalan peserta didik tentang agama Islam sehingga menjadi manusia muslim yang terus berkembang dalam hal keimanan, ketaqwaan, berakhlak mulia, berbangsa dan bernegara (Ilyas dkk, 2017). Untuk mencapai tujuan tersebut maka dibutuhkan proses yang mampu mengaktifkan siswa agar belajar menjadi bermakna. Namun pembelajaran PAI khususnya di Madrasah Ibtidaiyah / sekolah dasar masih belum mampu memberikan proses yang maksimal.

Berdasarkan hasil penelusuran, pembelajaran Pendidikan Agama Islam di jenjang sekolah dasar masih bersifat konvensional dan belum memaksimalkan 
bahan ajar lain. Bahan ajar yang digunakan oleh guru hanya buku paket dan dari pihak sekolah tidak ada inisiatif untuk mengembangkan bahan ajar terutama modul (Andri dkk, 2019; Fatimah, 2017). Senada dengan hal tersebut, berdasarkan hasil observasi dan wawancara yang dilakukan di Madrasah Ibtidaiyah (MI) Braja Indah Lampung Timur ditemukan bahwa selama ini sekolah masih belum memiliki persediaan media pembelajaran yang memadai termasuk modul pembelajaran. Beberapa media masih terbatas sehingga penggunaannya kurang efektif. Hal ini berakibat pada pembelajaran yang kurang maksimal.

Berdasarkan hal tersebut, maka penelitian ini bertujuan untuk mengembangkan modul pembelajaran Pendidikan Agama Islam (PAI) kelas IV Madrasah Ibtidaiyah. Hasil penelitian ini diharapkan dapat dijadikan sebagai bahan kajian bagi pengembangan baik bahan ajar maupun media pembelajaran berikutnya. Selain itu modul yang dikembangkan dapat digunakan sebagai media yang mendukung pembelajaran PAI di kelas IV Madrasah Ibtidaiyah atau di Sekolah Dasar.

\section{Metode}

Penelitian ini termasuk dalam penelitian pengembangan. Langkah penelitian yang digunakan merujuk pada Yusuf (2015), yaitu: 1) merumuskan masalah/tujuan penelitian, 2) melakukan studi pendahuluan, 3) merancang pengembangan, 4) melaksanakan penelitian sesuai dengan rancangan pengembangan, 5) mengevaluasi produk, analisis data, dan refleksi, dan 6) menyusun laporan hasil penelitian.

Validasi produk dilakukan dengan teknik focus group discussion (FGD). Peserta FGD terdiri dari dosen dan guru mata pelajaran. Uji coba dilakukan dengan menggunakan eksperimen The One Group Pretest-Posttest Design (Yusuf, 2015). Instrumen pengumpulan data terdiri dari angket validasi produk, soal tes, serta angket respon siswa. Subjek penelitian yaitu siswa kelas IV MI Braja Indah Lampung Timur. Analisis data mengenai keefektifan modul pembelajaran dilakukan dengan menganalisis perbedaan rerata nilai pretes dan postes.

\section{Hasil dan Pembahasan}

Proses pengembangan modul pembelajaran PAI dilakukan dalam beberapa tahap, yaitu:

a) Merumuskan masalah/tujuan penelitian.

Pada tahap ini sebelum merumuskan masalah peneliti melakukan studi pendahuluan. Studi pendahuluan dilakukan dengan cara observasi, wawancara, dan studi literatur mengenai masalah yang muncul dalam pembelajaran PAI di sekolah. Studi pendahuluan tahap ini memperoleh gambaran bahwa 
pembelajaran Pendidikan Agama Islam di jenjang sekolah dasar masih bersifat konvensional dan belum memaksimalkan bahan ajar lain. Bahan ajar yang digunakan oleh guru hanya buku paket dan dari pihak sekolah tidak ada inisiatif untuk mengembangkan bahan ajar terutama modul (Andri dkk, 2019; Fatimah, 2017). Demikain juga dengan hasil observasi dan wawancara yang dilakukan di Madrasah Ibtidaiyah (MI) Braja Indah Lampung Timur. Berdasarkan hasil observasi dan wawancara ditemukan bahwa selama ini sekolah masih belum memiliki persediaan media pembelajaran yang memadai termasuk modul pembelajaran. Beberapa media masih terbatas sehingga penggunaannya kurang efektif. Hal ini berakibat pada pembelajaran yang kurang maksimal.

Setelah mendapatkan permasalahan maka selanjutnya merumuskan masalah mengenai pengembangan modul pembelajaran PAI di Madrasah Ibtidaiyah. Menetapkan tujuan penelitian yaitu mengembangkan modul pembelajaran PAI di Madrasah Ibtidaiyah.

b) Melakukan studi pendahuluan.

Pada tahap ini melakukan studi pendahuluan terhadap literatur mengenai pengembangan modul pembelajaran. Studi literatur dilakukan melalui penelusuran tentang karakteristik dan desain modul pembelajaran. c) Merancang pengembangan.

Dalam penelitian ini pengembangan modul dilakukan dengan cara: (a) analisis kebutuhan modul, (b) mengembangkan modul, (d) melakukan validasi dan uji coba.

d) Melaksanakan penelitian sesuai dengan rancangan pengembangan.

Dalam penelitian ini pengembangan modul dilakukan sesuai dengan rancangan pengembangan yang telah disusun, yaitu:

1) Analisis kebutuhan modul, dilakukan dengan cara observasi dan wawancara mengenai ketersediaan modul di sekolah. Berdasarkan hasil observasi dan wawancara diperoleh gambaran bahwa belum tersedia modul pembelajaran untuk PAI. Guru juga tidak berinisiatif mengembangkan modul sendiri.

2) Mengembangkan modul. Pengembangan modul diawali dengan analisis materi. Analisis materi dilakukan dengan cara wawancara dengan guru mengenai pokok bahasan yang dirasa sulit dan cocok untuk dijadikan dalam bentuk modul. Berdasarkan hasil wawancara diperoleh materi kelas IV mengenai Sejarah Kebudayaan Islam. Materi ini memiliki kesulitan tersendiri karena membahas cerita-cerita masa lalu, sehingga siswa merasa kesulitan memahaminya. Sub pokok bahasan 
yang dikembangkan dalam modul ini yaitu Isra' Mi'raj.

Selanjutnya mengumpulkan materimateri yang relevan dan dianalisis mengenai keluasan serta kedalaman materi dalam modul. Langkah berikutnya mengembangkan desain sesuai dengan pedoman pengembangan modul pembelajaran.

Modul pembelajaran PAI ini terdiri dari: (a) judul modul, (b) kata pengantar, (c) daftar isi, (d) kompetensi/tujuan pembelajaran, (e) materi pembelajaran, (f) rangkuman, (g) soal/latihan, (h) kunci jawaban, dan (i) daftar pustaka.

3) Melakukan validasi dan uji coba. Validasi modul dilakukan dengan cara focus group discussion (FGD). Peserta FGD terdiri dari dosen dan guru pengampu mata pelajaran. Hasil FGD berupa catatan masukan, sebagai berikut: (a) tujuan pembelajaran pada modul belum dicantumkan dengan jelas sehingga masih membingungkan; (b) penataan bahasa harus disesuaikan lagi dengan sasaran pengguna; (c) desain warna dan ukuran huruf harus disesuaikan lagi agar lebih nyaman untuk dibaca. Masuka-masukan tersebut dijadikan bahan perbaikan modul.

Selanjutnya, uji coba modul dilaksanakan dengan menggunakan desain eksperimen The One Group Pretest-Posttest Design. Uji coba modul pembelajaran PAI ini dilaksanakan dengan langkah berikut: (a) proses pembelajaran diawali dengan pemberian soal pretes kepada siswa; (b) pembelajaran dilaksanakan dengan menggunakan modul yang telah dikembangkan. Dalam pembelajaran guru tetap memfasilitasi dan mendampingi siswa dalam belajar; (c) pembelajaran diakhiri dengan pemberian soal postes kepada siswa. Selain itu siswa juga diminta untuk memberikan masukan mengenai modul yang digunakan dalam belajar.

e) Mengevaluasi produk, analisis data, dan refleksi.

1) Evaluasi produk

Modul pembelajaran ini telah dikembangkan sesuai dengan karakteristik modul. Karakteristik modul meliputi: (a) Self instructional, (b) Self Contained, (c) Stand alone (berdiri sendiri), (d) Adaptif, dan (e) User friendly (Rahdiyanta, 2016). Dalam modul pembelajaran ini telah didesain agar dapat digunakan untuk belajar mandiri (self instruction), yaitu: (a) memuat tujuan pembelajaran yang jelas, (b) memuat materi pembelajaran yang dikemas dalam unit-unit yang spesifik, sehingga memudahkan dipelajari secara tuntas, (c) terdapat soal-soal latihan untuk 
mengukur penguasaan siswa,

(d)

menggunakan bahasa yang sederhana dan komunikatif, (e) terdapat rangkuman materi pembelajaran, (f) terdapat kunci jawaban sebagai instrumen penilaian, yang memungkinkan peserta didik melakukan penilaian mandiri (self assessment), dan (g) terdapat informasi tentang rujukan/ pengayaan/referensi yang mendukung materi pembelajaran dimaksud. Desain tersebut juga memenuhi karakteristik stand alone, dimana pengguna modul dapat belajar tanpa membutuhkan media lainnya. Modul PAI ini telah memenuhi karakteristik self contained. Materi yang termuat dalam modul ini dipecah menjadi beberapa unit kecil yang saling melengkapi. Muatan materi dalam modul ini terdiri dari: (a) pengertian Isra' Mi'raj, (b) sejarah Isra' Mi'raj, (c) terjadinya Isra' Mi'raj, (d) Isra' Mi'raj sebagai tasliyah, dan (e) hikmah peristiwa Isra' Mi'raj.

Modul pembelajaran ini juga adaptif dan user friendly. Hal ini tergambar dari penggunaan bahasa yang telah disesuaikan dengan sasaran usia pengguna.

2) Analisis data

Data yang diperoleh dari hasil uji coba di kelas berupa nilai pretes dan postes. Berikut hasil uji coba modul pembelajaran PAI:
Tabel 1. Nilai Hasil Uji Coba

\begin{tabular}{|c|c|c|}
\hline Subjek & Pretes & Postes \\
\hline Subjek 1 & 60 & 80 \\
\hline Subjek 2 & 50 & 70 \\
\hline Subjek 3 & 70 & 100 \\
\hline Subjek 4 & 50 & 90 \\
\hline Subjek 5 & 60 & 90 \\
\hline Subjek 6 & 40 & 90 \\
\hline Subjek 7 & 70 & 80 \\
\hline Subjek 8 & 80 & 90 \\
\hline Subjek 9 & 60 & 90 \\
\hline Rerata Nilai & $\mathbf{6 0}$ & $\mathbf{8 6 , 7}$ \\
\hline
\end{tabular}

Berdasarkan hasil uji coba terlihat bahwa nilai rerata pretes dan postes mengalami perbedaan. Rerata nilai pretes sebesar 60 mengalami kenaikan rerata nilai sebesar 86,7 .

\section{3) Refleksi}

Berdasarkan hasil pretes dan postes menunjukkan adanya kenaikan rerata nilai. Hal ini menunjukkan bahwa penggunaan modul pembelajaran dapat meningkatkan hasil belajar siswa. Hasil uji coba ini senada dengan hasil penelitian dari Susanti (2017) yang mengembangkan modul pembelajaran PAI Berbasis Kurikulum 2013 Di Kelas V SD Negeri 21 Batubasa, Tanah Datar. Dalam penelitian tersebut nilai rerata yang diperoleh setelah menggunakan modul pembelajaran PAI sebesar 85,50 dari KKM 75. Penggunaan modul pembelajaran juga mempengaruhi hasil belajar sebanyak 85\% di Madrasah Ibtidaiyah 3 Penatarsewu (Yati, 2019).

Berdasarkan hasil observasi pelaksanaan, pembelajaran dengan 
menggunakan modul berjalan dengan lancar. Siswa lebih tertarik belajar menggunakan modul. hal ini dikarenakan modul yang dikembangkan memiliki warna yang menarik. Penggunaan warna merupakan aplikasi dari prinsip desain pesan pembelajaran yaitu prinsip pemusat perhatian. Prinsip ini menyatakan bahwa jika dalam penyampaian pesan digunakan alat pemusat perhatian, maka hasil belajar akan meningkat. Jika perhatian peserta didik terpusat pada pesan yang dipelajari maka proses dan hasil belajar akan lebih baik (Gafur, 2015).

Pada saat menggunakan modul, siswa dapat mengukur kemampuan diri sendiri melalui soal yang disajikan. Hal tersebut sebagai upaya memberikan umpan balik terhadap hasil belajar siswa. Tujuan utama dari umpan balik adalah untuk mengurangi kesenjangan yang ada antara pemahaman saat ini dan pemahaman yang diinginkan dalam kaitannya dengan tugas (Yusoff, 2013). Pemberian umpan balik juga dapat mempengaruhi motivasi belajar (Strube \& Strand, 2015). Siswa dapat merasakan kefektifan diri yang tinggi ketika tahu dirinya mampu belajar dari sumber yang dapat dipercaya (Schunk, 2012).

Basri (Hildayatni, 2019) menyampaikan bahwa dengan menggunakan modul siswa memiliki kesempatan untuk menguji dirinya sendiri melalui latihan-latihan soal yang ada dan mengembangkan kemampuan siswa untuk berinteraksi dengan lingkungan sekitar sehingga pengetahuan siswa tidak hanya diperoleh di dalam kelas namun juga di luar kelas.

f) Menyusun laporan hasil penelitian.

Pada tahap ini menyusun hasil penelitian. Hasil penelitian disusun sesuai dengan tahapan yang dilaksanakan.

\section{Kesimpulan}

Pengembangan modul pembelajaran PAI ini dilaksanakan dalam enam tahap, yaitu (1) merumuskan masalah/tujuan penelitian, (2) melakukan studi pendahuluan, (3) merancang pengembangan, (4) melaksanakan pengembangan, (5) mengevaluasi produk, analisis data, dan refleksi, dan (6) menyusun laporan hasil penelitian. Hasil uji coba menunjukkan peningkatan nilai rerata siswa. Hal ini dapat dikatakan bahwa modul pembelajaran PAI efektif digunakan dalam pembelajaran.

Kelebihan dari modul pembelajaran PAI ini yaitu lebih menarik, mudah digunakan serta dapat dipelajari oleh siswa secara mandiri. Disamping kelebihan, dalam modul ini masih terdapat kekurangan yaitu belum terdapat ruang untuk berkolaborasi dalam belajar melalui modul tersebut. Selain itu, masih membutuhkan uji coba dengan subjek yang lebih luas agar efektifitas modul menjadi lebih valid. Oleh sebab itu, terbuka sekali bagi penelitian selanjutnya baik untuk uji coba 
maupun mengembangkan modul ini lebih lanjut.

\section{Daftar Pustaka}

Ahdiyanto, E. 2016. Pengembangan Modul Pembelajaran Geometri Bangun Datar Berbasis Teori Van Hiele untuk Siswa Kelas VI Sekolah Dasar. Jurnal Pendidikan Dasar Nusantara. Volume 1 Nomor 2 Januari 2016. https://ojs.unpkediri.ac.id/index.php/pgs d/article/view/219

Alannasir, W. 2016. Pengaruh Penggunaan Media Animasi Dalam Pembelajaran Ips Terhadap Motivasi Belajar Siswa Kelas IV SD Negeri Mannuruki. Journal of Education and Science Technology. Volume 2 Nomor 2 Agustus 2016 . DOI: https://doi.org/10.26858/est.v2i2.2561.

Andri, Suswati Hendriani, Fadriati. 2019. Pengembangan Modul Pendidikan Agama Islam Dan Budi Pekerti Dengan Pendekatan Project Based Learning bagi Siswa SDN 22 Baringin Kecamatan Lima Kaum. Jurnal el-Hekam, Vol. IV, No. 2, Juli-Desember 2019. http://ecampus.iainbatusangkar.ac.id/ojs/i ndex.php/elhekam/article/view/2016/151 $\underline{9}$

Fatimah, S. 2017. Pengembangan Modul Pendidikan Agama Islam Berbasis Pendekatan Saintifik Kurikulum 2013 Pada Siswa Kelas IV SDN Warugunung 1 Surabaya Semester I. Tesis. Pascasarjana IAIN Sunan Ampel. https://core.ac.uk/download/pdf/1516169 51.pdf

Gafur, A. 2015. Desain Pembelajaran: Konsep, Model, dan Aplikasinya dalam Perencanaan Pelaksanaan Pembelajaran. Yogyakarta: Ombak

Hildayatni. 2019. Pengaruh Penggunaan Modul Pembelajaran IPA Terintegrasi Nilai Agama terhadap Peningkatan Karakter Rasa Ingin Tahu Siswa. Muallimuna: Jurnal Madrasah Ibtidaiyah. Vol. 5, No.
1, Oktober 2019.

DOI: http://dx.doi.org/10.31602/muallim una.v5i1.2009

Ilyas, A., Effendi, Z., Gistituati, N., \& Ananda, A. 2017. Pengembangan Model Pembelajaran Inkuiri dalam Mata Pelajaran Agama Islam (PAI) Di Sekolah Dasar. 2nd International Seminar on Education 2017 Empowering Local Wisdom on Education for Global Issue. http://ecampus.iainbatusangkar.ac.id/ojs/ index.php/proceedings/article/view/849

Prastowo, A. 2011. Panduan Kreatif Membuat Bahan Ajar Inovatif. Yogyakarta: Diva Press.

Putri, W. 2017. Pengaruh Media Pembelajaran Terhadap Motivasi Belajar Bahasa Arab Siswa Madrasah Tsanawiyah. Lisania: Journal of Arabic Education and Literature Vol.1, No.1, 2017, pp.1-16. DOI:

http://dx.doi.org/10.18326/lisania.v1i1.116

Rahdiyanta, D. 2016. Teknik Penyusunan Modul. http://staff.uny.ac.id/sites/default/files/pe nelitian/dr-dwi-rahdiyanta-mpd/20teknik-penyusunan-modul.pdf

Schunk, D., Pintrinch, P., \& Meece, J. 2012. Motivasi dalam Pendidikan: Teori, Penelitian dan Aplikasi, Edisi Ketiga. Terjemahan. New Jersey: Pearson Education Inc.

Smaldino, S. E., Lowther, D. L., \& Russell, J. D. (2012). Instructional Technology and Media for Learning. Boston: Pearson Education Inc.

Srinadi, N. 2015. Analisis Pengaruh Penggunaan Teknologi Informasi Sebagai Media Pembelajaran Terhadap Motivasi Belajar Siswa. Konferensi Nasional Sistem \& Informatika 2015 STMIK STIKOM Bali, 9 - 10 Oktober 2015

Susanti, R. 2017. Pengembangan Modul Pembelajaran PAI Berbasis Kurikulum 2013 di Kelas V SD Negeri 21 Batubasa, Tanah Datar. JMKSP Jurnal Manajemen, 
Kepemimpinan, dan Supervisi Pendidikan Volume 2, No. 2, Juli-Desember 2017

Strube, G., \& Strand, B. 2015. Can Feedback Affect Motivation? Journal of The Oklahoma Association for Health, Physical Education, Recreation, and Dance, Vol 52, No 2. https://www.researchgate.net/publication 1280098357_Can_feedback_affect_motiv ation

Yati, I. 2019. Implementasi Media Cetak dalam Pembelajaran Inovatif pada Tingkat Madrasah Ibtidaiyah. Universitas Muhammadiyah Sidoarjo. http://eprints.umsida.ac.id/6342/

Yusoff, M. 2013. Using Feedback to Enhance Learning and Teaching. USM Pulau Pinang: Centre for Academic Excellence \& Student Advisory and Development (CDAE)

Yusuf, A. 2015. Metode Penelitian: Kuantitatif, Kualitatif, dan Penelitian Gabungan. Jakarta: Kencana 